\title{
ATUAÇÃO DE MULHERES NA LIDERANÇA DE PROJETOS (COM IMPACTOS SOCIAIS) COMO MECANISMO DE TRANSFORMAÇÕES SOCIAIS E GOVERNANÇA
}

\author{
ROLE OF WOMEN IN PROJECT LEADERSHIP (WITH SOCIAL IMPACTS) AS A \\ MECHANISM FOR SOCIAL CHANGE AND GOVERNANCE
}

Líliam dos Santos Vasconcelos ${ }^{1}$

Vanessa Santos da Paixão Miranda ${ }^{2}$

\begin{abstract}
RESUMO: Este trabalho ocupa-se da abordagem otimista quanto à mulher na atuação de liderança de projetos com grande impacto na sociedade. Desde a constituição e administração da família ao trabalho fora de casa, ela vem a demonstrar destaque porque além de gerir com excelência as relações interpessoais, pela sua sensibilidade aguçada, ela tem a característica singular de profissional multifacetada. Seja trabalho doméstico ou profissional, quando executado pelo talento feminino, direciona-se a um caminho promissor com potencial de transformação social e assim o faz, com o seu poder de governança que começou a ser aprimorado no seu lar e expandiu-se para o ambiente corporativo e para o empreendedorismo de impacto social. A sua representatividade corrobora com resultados significativos no desenvolvimento pessoal e socioeconômico, além de articular mecanismos multiplicadores de mudança social, integrados por atuações cooperativas e solidárias que ensejam maior participação popular e democrática.
\end{abstract}

Palavras-chave: Mulher líder. Projetos sociais. Transformação social. Democracia. Governança.

ABSTRACT: This work deals with the optimistic approach towards women in the role of leadership in projects that have a great impact on society. From the establishment and administration of the family to working outside the home, she has shown prominence because in addition to managing interpersonal relationships with excellence, due to her keen sensitivity, she has the unique characteristic of a

'Mestrado do curso de Direito, Governança e Políticas Públicas da UNIFACS-Universidade Salvador.CAPES - orcid.org/oooo-ooo2-7003-6223); Pós-graduanda em Ciências Criminais com ênfase em Direito Penal Econômico; Bacharela em Direito; e Bacharela em Humanidades com Área de Concentração em Estudos Jurídicos. E-mail: liliamvasconcelos@hotmail.com.

${ }^{2}$ Mestrado do curso de Direito, Governança e Políticas Públicas da UNIFACS-Universidade Salvador. Especialista em Auditoria Governamental. Auditora Interna da Prefeitura Municipal de Camaçari. Email:vanpaixao2s@hotmail.com. 
multifaceted professional. Whether domestic or professional work, when performed by female talent, it leads to a promising path that has the potential for social transformation and it does so, with its governance power that began to be improved at home and expanded to the corporate environment and for social impact entrepreneurship. Its representativeness corroborates with significant results in personal and socioeconomic development, in addition to articulating multiplier mechanisms for social change, integrated by cooperative and solidary actions that lead to greater popular and democratic participation.

Keywords: Woman leader. Social projects. Social transformation. Democracy. Governance.

\section{INTRODUÇÃO}

O presente trabalho aborda o caminhar evolutivo da mulher, iniciado em casa, através do desenvolvimento do trabalho doméstico e, atualmente, após ultrapassar barreiras como machismo e exclusão, tem sido destaque em organizações que promovem a transformação social.

A relevância deste estudo escora-se em compartilhar contribuições acerca da ressignificação da valorização da mulher quanto a sua atuação de liderança, com destaque aos projetos, que têm sido responsáveis pelas transformações sociais que mitigam as necessidades urgentes da sociedade, além de criar espaços para serem inseridas novas perspectivas com oportunidades da atuação integrativa estatal através de políticas públicas que tenham como finalidade a redução das desigualdades sociais, econômicas e culturais.

Atualmente, o cenário apresenta mulheres em cargos de maior poder e prestígio nos mais diversos setores profissionais, e em muitos desses quase que se equiparando aos homens em questão de quantidade, investindo cada vez mais em uma boa formação (Teycal \& Coutinho, 2007).

O percurso deste ensaio será feito em três momentos. A princípio, será discorrido sobre a importância das mulheres como base de sustentação das famílias, por meio da governança que ela sempre executou sem se dar conta. E, ainda assim, teve êxito no controle interno doméstico e educação dos filhos, ressaltando com essa abordagem a perseverança e coragem da mulher em lutar pela ruptura de paradigmas que durante muito tempo determinaram as suas possibilidades. Em seguida, uma breve 
exposição dos negócios de impactos sociais idealizados e implementados por mulheres, cuja abrangência contempla a vida de outras pessoas a nível nacional e internacional. Logo depois, será debatida a correlação entre a atuação das mulheres e os seus papéis como atores que, por meio da sua expertise e força de vontade, conseguem ser mobilizadoras de mudanças importantes na configuração de um modelo de governança que contempla a democracia participativa. Por fim, suscita-se uma reflexão a respeito do papel do estado e o seu modelo de governança, diante da exigência popular de uma redemocratização eficaz na desestagnação do desenvolvimento social de categorias que atualmente são sub-representadas.

\section{A importância das mulheres como base de sustentação das famílias: da governança doméstica à liderança institucional}

Das instituições sociais criadas pela humanidade, a família é a mais antiga delas. A partir do sedentarismo, marcado pela transição cultural do ser nômade para o ser permanente, a família patriarcal é considerada um dos primeiros modelos. Embora chefiada pelo homem, a mulher já desempenhava um importante papel: a de administradora do lar, dos cuidados com os filhos, com o marido e com todos em simultâneo, incluindo-se, em alguns casos, com a mãe, com o pai e até com os sogros.

A mulher é colocada como um elemento agregador imprescindível, sem o qual a unidade familiar não sobrevive (Favaro, 2007). Ou seja, ainda que o homem tivesse a incumbência de manter as despesas materiais, a sustentação quanto ao equilíbrio emocional e mediação de conflitos eram tarefas exclusivamente femininas no âmbito familiar.

Séculos passaram-se, a humanidade evoluiu socialmente em muitos aspectos, a exemplo da visão e concepção familiar. Hoje, não necessariamente a mulher deseja ter filhos ou casar-se. E não necessariamente o seu relacionamento amoroso é com um homem. As formas de construção familiar são diversas entre os gêneros. E embora ela ainda seja a principal realizadora das tarefas domésticas, esse cenário também vem a sofrer constantes transformações.

Devido a sua criação embasada em costumes tradicionalmente machistas, restou à mulher aprender, e assim o efetuou com excelência, a cuidar das tarefas 
peculiares da casa e incumbida da educação doméstica dos filhos. A necessidade de conciliar inúmeras atribuições também vinculadas à organização doméstica e controle a transformou em uma espécie de controladora interna, pois ainda que o homem fosse o provedor no âmbito econômico, com ela estava as informações principais sobre a família, sobre o funcionamento operacional da casa. Se estabelecia aí uma governança do lar, que não é a praticada pelas empresas, pelas grandes corporações, mas é a que mantém uma família alimentada nos horários, após a logística da compra dos mantimentos, e preparasse as refeições; ambiente limpo, crianças bem-educadas, esposo satisfeito e, ainda mais, afeto para manter as relações harmoniosamente.

As habilidades desenvolvidas para cuidar culminaram em talento para administrar mais que a casa onde vive, mas, antes de qualquer outra coisa, a sua própria vida, a partir da união de muitas outras, através de movimentos e reivindicações diversas.

Duarte (2003) destaca como a movimentação feminista adentrou no século XX, reivindicando direitos em diversos âmbitos, denunciando opressões e discriminações, criando associações e movimentos cujas conquistas, ainda que à custa de muito esforço, acumulara-se até o ponto de se inserirem em espaços nobres, notadamente, masculinos: o mundo intelectual, especialmente, o das letras e da imprensa. Sarti (2004) observa que a partir da década de 1970 verifica-se a eclosão do feminismo brasileiro, causada, dentre outros fatores, pela declaração do Ano Internacional da Mulher, em 1975, pela ONU. Entretanto, a autora não despreza a relevância das mudanças ocorridas no Brasil, em virtude da modernização pela qual o país atravessou na década anterior, para a expansão dos movimentos feministas e das questões que se referiam à identidade de gênero que, segundo Sarti (2004, p. 40), "ganharam espaço quando se consolidou o processo de abertura política no país no final da década de 1970". 3

Com a concretização de consideráveis conquistas, como o direito ao voto e a inserção no mercado de trabalho formal, a mulher foi se tornando também referência de transformações sociais. Ela é exemplo de resiliência. Na perspectiva de Grant

${ }^{3}$ MEDEIROS, Cintia Rodrigues de Oliveira. Mulheres no terceiro setor : "mirem-se ... no exemplo... daquelas mulheres... de Atenas / Dissertação de mestrado. Universidade Federal de Uberlãndia, 2008. 
(200I), a mudança ocorrida com a entrada da mulher no mundo profissional, a conquista de poder decidir sobre o momento de ter, ou mesmo de não ter filhos em decorrência dos métodos anticoncepcionais, o divórcio e a possibilidade de estabelecer novas parcerias amorosas, pluralizaram os signos que permitem a sua inscrição numa determinada rede social. Neste contexto, pode-se dizer que está a haver uma reinvenção, onde a mulher assume novos papéis e novos desafios.

Importante citar nesse contexto que por mais que as mulheres estejam a adentrar esse novo mundo de oportunidades fora do ambiente familiar, por mais que consigam conciliar inúmeras atividades, não significa que não estejam sobrecarregadas. Destaca-se aqui a urgência em romper com o mito da heroína do lar, mesmo porque a romantização do complexo de Amélia já não é mais a realidade da maioria, além de prejudicar o processo de libertação que tanto as mulheres buscam.

Não somente a mulher vem a vivenciar reestruturações, o mundo do trabalho também, que, inclusive, a acolhe com muito mais frequência, apesar de ainda não ter alcançado o nível de equidade correspondente ao do homem. Como parte dessas estruturações, há a necessidade de um olhar mais atento às iniciativas vinculadas à economia solidaria, que tem crescido no Brasil. Devido aos altos índices de desemprego e subemprego, que se configuram impedimento ao acesso das necessidades básicas, as pessoas buscam caminhos alternativos.

Segundo Oliveira (2004), a economia solidária tem a sua emergência na realidade brasileira a partir da década de 8o, se intensificando na década de 90. Caracteriza-se em uma resposta à crise do mundo do trabalho, bem como um posicionamento dos trabalhadores e da sociedade civil em contraposição aos reflexos trazidos pela acumulação flexível. Desta forma, emerge no movimento da sociedade civil, a partir de vários sujeitos e grupos que ao longo da trajetória histórica vêm a tecer não apenas uma alternativa de geração de trabalho e renda para a classe trabalhadora, mas principalmente relações econômicas, políticas e sociais pautadas em uma lógica não capitalista.

Há, nesse contexto, predominância das mulheres, bem como o seu protagonismo e a capacidade de constituir espaços de geração de trabalho e renda a partir das atividades apreendidas ao longo da socialização: cozinhar, limpar, costurar, 
bordar, fazer artesanato. Essas atividades constituíram-se como pertencentes ao espaço privado ou atividades "tidas como femininas" e é essa justamente a grande força da Economia Solidária (OLIVEIRA, 2004)

A economia solidária compreende a luta da mulher e atua firmemente no combate à discriminação de gênero. Fomenta a democracia em todas as suas instâncias. É um moimento de resistência, assim como a história de superação feminina. Contempla a mulher também por abranger iniciativas diversas como cooperativas e associações. E qualquer que seja, a cooperação se faz presente.

O avanço das mulheres e a obtenção da igualdade entre mulheres e homens são facetas dos direitos humanos e condição para a justiça social e não devem ser tomados isoladamente, como uma questão de interesse apenas das mulheres. São o único meio de construir uma sociedade viável, justa e desenvolvida. O empoderamento das mulheres e a igualdade de gênero são pré-requisitos essenciais para alcançar a segurança política, social, econômica, cultural e ambiental entre todos os povos (BEIJING, 1995, art. 4I).

Ampliar o acesso das mulheres à cidadania significa valorizar a trajetória das suas lutas e reivindicações para inserir-se nos processos decisórios, no combate à discriminação, ao machismo, a dupla jornada de trabalho, haja vista que homens e mulheres vivenciaram e vivenciam trajetórias históricas, culturais, sociais, políticas diferenciadas," o reconhecimento público da diferença de gênero, permite redesenhar o traçado da cidadania, não só no feminino, mas em geral” (GALEOTTI, I995 p.236). Indicador de combate à injustiça social.

Além do impulsionamento que a economia solidária tem sido ao empoderamento feminino, o terceiro setor também o tem rendido destaques significativos. Mesmo porque segundo Offe (1989) há uma emergência de atividades do Terceiro Setor em um momento em que há a precarização das condições de trabalho. O sistema ocupacional, ao reduzir a sua capacidade de absorção do mercado, exclui aqueles que não conseguem o trabalho remunerado, levando-os à crença de que são fracassados (OFFE, 1999), haja vista que o trabalho remunerado é condicionante para a participação da vida na sociedade capitalista. Assim, o terceiro setor alimenta a ideia de que pode constituir-se em um espaço que promete preencher as lacunas 
deixadas pela não atuação do Estado e do Mercado, abrangendo atividades diversas, e, principalmente, a força de trabalho feminina que vislumbra a possibilidade de avanço no processo de emancipação da mulher como ser social.

As entidades e instituições que deram origem ao que atualmente denominamse organizações do terceiro setor, na sua maioria, faziam parte do território feminino justamente por sua finalidade assistencial, pelo trabalho voluntário, o cuidado com o próximo, e outras características que sugerem a continuidade dos afazeres domésticos. A presença das mulheres continua a ser expressiva no setor, embora um significativo contingente de homens o tenha considerado como um campo profissional a ser explorado, assumindo posições associadas às responsabilidades "masculinas", o que acentua a "divisão do trabalho" entre os sexos no setor, abrindo uma lacuna a ser investigada quanto às relações de gênero e poder no âmbito dessas organizações (MEDEIROS, 2008).

Ressalta-se que o terceiro setor ${ }^{4}$, assim como a economia solidária, trata-se de um espaço propício à emancipação da mulher. Há uma reconfiguração quanto ao vínculo de poder entre os gêneros. No caso específico aqui abordado, a predominância é para mulheres que ocupam cargos de liderança e são um diferencial nessa posiçãochave porque fomentam encorajamento a outras mulheres.

2.I Mulheres brasileiras que se destacaram no empreendedorismo e nos projetos de impacto social e o reflexo desses resultados na gestão e governança de um estado

O papel social que a mulher busca representar está normalmente ligado ao seu ambiente de experiência, ao seu meio social, e por esse motivo tende a interferir no contexto que está ao seu alcance. Algumas buscam a sua realização em um espaço mais distante da sua realidade, porque esses espaços já existem na sua esfera de expectativa pessoal. São os ambientes onde elas gostariam de estar, de fazer parte e, por isso, algumas se projetam para fora do seu ambiente cotidiano. Outras saem do seu contexto, do seu meio e vão buscar as suas oportunidades, mas voltam para tentar

\footnotetext{
${ }^{4}$ Falconer (2004) sugere que o Terceiro Setor deve ser pensado como uma tipologia organizacional, cujas organizações, pretensamente, são qualificadas por apresentarem diferentes padrões de intervenção e serem desvinculadas da ordem econômica dominante.
} 
resgatar outras. São experiências diferentes baseadas em anseios e estímulos diferentes, mas todas são válidas. E assim, pode-se dizer que tem se contribuído à historicidade das lutas femininas.

São projeções que lhes tiram da zona de conforto e as fazem ir além. Essa é uma característica da mulher que idealiza e realiza, da mulher que faz parte do grupo das que guerreiam em prol de erguer a si, e muitas vezes erguer outras. Toda essa interface comportamental e idealista está ligada a uma série de fatores determináveis ou determinantes, tanto para quem parte para mudança quanto para quem aguarda ser alcançada pela mudança.

A diferença entre determinável e determinante é o resultado da força das influências ou impactos com a vida de cada uma dentro da sua subjetividade e realidade, fatores positivos ou negativos, a exemplo dos estereótipos de gênero, aspectos socioeconômicos, discriminações e reflexos de problemas da desigualdade, questões familiares, psicológicas, emocionais e todos os outros possíveis fatores que juntos dilatam a interseccionalidade feminina.

Fatores determináveis são aqueles que podem vir a influir nos processos de transição e evolução, positiva ou negativamente, mas que por motivos diversos os efeitos, por mais impactantes que sejam, direcionam a um resultado diferente do que o comum associado a certa circunstância. Já os fatores determinantes são aqueles que condicionam e comprometem o exercício do seu livre arbítrio. Em suma, aqueles fatores estão relacionados à presença do livre arbítrio, ou passo que esse está relacionado à ausência do livre arbítrio.

A importância de retratar os dois vieses é denotar a imprescindibilidade de se analisar as circunstâncias dos casos concretos, para que assim se compreenda o valor das pequenas ações e das pequenas mudanças. Emerge dessas premissas a essência da representatividade feminina e o valor inenarrável de cada ação voltada para o social. É o caso dos projetos de impactos sociais idealizados, liderados e realizados por mulheres, pois têm por propósito resgatar outras mulheres do patamar do abismo do determinismo e promovê-las ao espaço de acessibilidade do determinável. Ou seja, tem por essência viabilizar a oportunidade e mudar a realidade daquelas que antes não podiam projetar algum tipo de evolução e que a partir de uma intervenção podem, se 
assim quiserem.

São os níveis de limitações e restrições entre o determinável e o determinante que constituem os dois extremos que mobilizam ou imobilizam o desenvolvimento das pessoas. Em se tratando de projetos com impacto social, idealizados ou liderados por mulheres, a maioria visa a mitigação dos problemas sociais que ensejam em algum tipo de vulnerabilidade.

No Brasil, são muitos os projetos e negócios que têm esse cunho social, essa filosofia de existência. Existem pessoas que já trabalham essa perspectiva e realidade como um propósito e missão de vida. Muitas delas nem sequer são conhecidas pela mídia. No entanto, há muitos exemplos visíveis e disseminados que são reconhecidamente impactantes e que já representam grandes negócios e grandes iniciativas. São projetos que visam promover a sustentabilidade e o desenvolvimento socioeconômico de mulheres em situação de vulnerabilidade. E sobre esses cases de sucesso, podem funcionar como inspiração e exemplo, para fins de réplica os seguintes: MULHERES DO BRASIL, presidido pela empresária Luiza Helena Trajano (Magazine Luiza) s; REDE MULHER EMPREENDEDORA criado por Ana Fontes ${ }^{6}$;

REDE ASTA, fundada em 2005 por Alice Freitas e Rachel Schettino7; PROJETO MULHERES INSPIRADORAS, criado pela professora Gina Vieira ${ }^{8}$; MULHERES QUE INSPIRAM, criado por Priscilla Adduca ${ }^{9}$; FEMINARIA, a advogada Ana Carolina Bavon quem fundou ${ }^{\mathrm{io}}$; ESCOLA DE VOCÊ, criado pelas jornalistas Ana Paula Padrão e Natalia Leite ${ }^{\mathrm{II}}$; EMPREENDER MULHER, idealizado pela consultora de marketing Adriana Valente ${ }^{\mathrm{I} 2}$; _MIA - MULHERES INVESTIDORAS ANJO, criado pela empresária Maria Rita Spina ${ }^{13}$; TEM QUEM QUEIRA, projeto criado pela

\footnotetext{
${ }^{5}$ https://www.grupomulheresdobrasil.org.br/

${ }^{6}$ Fonte: https://rme.net.br/ , Acesso em: 09/07/2021

7 https://www.redeasta.com.br/

${ }^{8}$ https://institutoreacao.org.br/s-projetos-sociais-para-mulheres/

9 https://www.mulheresqueinspiram.com/

ro https://www.escoladevoce.com.br/

${ }^{\text {II }}$ https://www.escoladevoce.com.br/

${ }^{12}$ https://imulherempreendedora.com.br/posts/gestao/mulheres-que-apoiam-mulheres-9projetosinspiradores-para-voce-conhecer

${ }^{13}$ https://imulherempreendedora.com.br/posts/gestao/mulheres-que-apoiam-mulheres-9projetosinspiradores-para-voce-conhecer
} 
publicitária Adriana Gryner ${ }^{\mathrm{i} 4}$; O POVO CONTA, partindo da iniciativa da professora Ana Cláudia Santos5; ONG BANCO DE ALIMENTOS, fundado por Luciana Quintão ${ }^{16}$; VOLUNTEER VACATIONS criado por Mariana Serra ${ }^{17}$; FUNDO ELAS, um fundo de investimento social; MOVIMENTO MULHER 360; A COMPASSIVA ${ }^{18}$ é uma organização social; O RME CONECTA; CONSULADO DA MULHER ${ }^{19}$; MÃES DA FAVELA ${ }^{20}$; A REDE MAPA ${ }^{21}$; GRUPO FLORISTAS; REDE MANUAL ${ }^{22}$.

Todas as mudanças promovidas por essas inciativas têm surtido efeitos significativos para a sociedade em decorrência da promoção do empoderamento ensejado por um alcance maior da representatividade feminina. Esse movimento de mobilizações vem a criar uma consciência coletiva sobre direitos inerentes à mulher, tais como aqueles que lhe concedem o direito à igualdade para ocupação de espaços e conquista de autonomia, ocasionando uma grande cadeia de valor dentro do organismo social. Essa evolução molda um novo cenário de governança, onde requer novas formas de gestão bem como uma nova visão sobre a inserção e espaço de atuação de novos atores no cenário organizacional:

[...] boas práticas contemporâneas de gestão organizacional recomendam confiança, abertura, diálogo, tolerância a erros e incentivo ao espírito empreendedor. $\mathrm{O}$ modelo gerencial da nova era exige que se mudem os antigos, já superados e tipicamente masculinos conceitos de competição e agressão pelos de cooperação e relações de afetos, essenciais ao processo de humanização. (Silva, 2000. p. 173).

\footnotetext{
${ }^{14}$ Fonte: http://www.temquemqueira.org.br/. Acesso em: 08/o7/2021.

is https://www2.educacao.mg.gov.br/component/gmg/story/6491-educadora-mineira-participa-daetapa-final-do-premio-educador-nota-ıo.

$/{ }^{16}$ Fonte: https://bancodealimentos.org.br/, Acesso em: II/o7/202I

${ }^{17}$ Fonte: https://volunteervacations.com.br/quem-somos. Acesso em: II/o7/2021

${ }^{18}$ Fonte: https://compassiva.org.br/quem-somos/. . Acesso em:10/o7/2021

19 Fonte: tps://imulherempreendedora.com.br/posts/gestao/mulheres-que-apoiam-mulheres-9projetos-inspiradores-para-voce-conhecer. Acesso em: 12/07/2021. "Criado em 2011, por uma iniciativa do Walmart, visa contribuir para o empoderamento econômico feminino, seu foco é a promoção da equidade de gênero e o crescimento da participação das mulheres no meio corporativo, se tornando uma associação independente sem fins lucrativos em 2015, busca engajar empresas para trabalharem seu público interno feminino e, gradativamente, expandir suas ações para as comunidades e cadeias de suprimentos, hoje, o movimento tem como sócio-fundadoras empresas como Natura, Unilever, CocaCola, Bombril, entre outras".

${ }^{20}$ Fonte: https://www.maesdafavela.com.br/. Acesso em: II/o7/2021

${ }^{21}$ Fonte: https://www.queroacolher.mapadoacolhimento.org/ Acesso em: II/o7/202I

${ }^{22}$ Fonte: http://redemanual.com.br/ Acesso em: II/o7/2021
} 
A mulher tem ocupado espaços, mas ainda não o suficiente quando se trata de uma sociedade complexa nas suas carências sociais e económicas. Essa é uma demanda que reverbera na necessidade de união de forças, em todos os sentidos, seja na contribuição intelectual, cooperativa, humanitária, trabalho, geração de renda, afeto, fraternidade e compaixão, para que assim seja possível atender as demandas trazidas pelas crises atuais que se somam às mazelas já existentes na sociedade.

Visto isso, o contexto da contemporaneidade suscita uma congruência de elementos que precisam ser relevados para uma visão organizacional mais humanitária em que a força do capital não seja o instrumento principal, que se pondere e considere às capacidades humanas de promoverem mudança social. E esse mecanismo precisa passar por um modelo de gestão mais humanitária que seja contemplada ao incorporase em novas formas de governança que visem a efetividade de uma democracia autêntica e eficaz, ou seja, uma que não sub-represente, não exclua e nem segregue.

\subsection{Direito e poder: mulheres transformadas transformam mais - da sub-representação à promoção da democracia participativa}

A predominância de pensamento materialista que considera que os negócios idealizados, estruturados ou mantidos por mulheres estão sempre relacionadas a atividades, ou geração de produtos sem poder de escala. Traduz no mundo dos negócios mais um tipo de estereótipo de gênero que faz sub-representar a capacidade de liderança, gestão e politica da mulher. Ou seja, os empreendimentos dirigidos por mulheres estariam ligados à produção de produtos manuais de pouco poder de venda, produção e distribuição, como, por exemplo, a produção de artesanato, corte e costura, culinária e trabalho doméstico.

Seriam esses um dos motivos possíveis de ser apontados como paradigmas que demonstram o porquê que esses projetos não dispunham de incentivos fortes ou financiamentos, pois representariam negócios de naturezas pouco escaláveis em detrimento da produção de um produto altamente replicável e com grande poder de produção ou industrialização, que torna esses negócios característicos e propícios à categoria de projetos a serem desenvolvidos por ONGs ou cooperativas, cuja essência e finalidade estariam direcionadas para um amparo apenas social e filantrópico. 
Essa visão constitui uma ideologia que traz um problema para esse tipo de iniciativas tendendo a sucumbir muitas possibilidades, pois a crença da pouca lucratividade mitiga inclusive as oportunidades de atuação de mulheres, que, embora não disponham de um nível de escolaridade elevado, detenham em contrapartida habilidade específica e importante que poderia com certo investimento ser potencializada. Essa conjunção de fatores limitantes empregados nesse setor desclassifica, desvaloriza e subestima tanto a capacidade e habilidade de mulheres quanto dos negócios idealizados e realizados por elas, os colocando em uma categoria de produção restrita, de cunho predominantemente subsistente ou de urgência sob a máxima do que popularmente é repetido nas falas: "vendem o almoço para pagar o jantar!” Essa é uma crítica discriminatória e preconceituosa que só serve para reforçar a necessidade de se pensar interseccionalidade feminina ao considerar formas de resoluções de problemas inerentes à mulher e que a afeta em escala global.

É indubitável que a criatividade e talento são habilidades inerentes ao perfil da mulher, embora considerados como características necessárias apenas para uma subcategoria de negócio que não detém grandes poderes de escala e lucro por produção. Por isso, pouco valorizada e disseminada.

\footnotetext{
“[...] à performance de sucesso em uma área, diz respeito a variáveis psicossociais associadas ao esforço, ao acesso a oportunidades, e como as pessoas respondem às chances que lhes são apresentadas. Neste sentido, compreendemos a emergência do talento feminino como um processo dinâmico e multifacetado que privilegia a interação de fatores contextuais, sociais, personológicos e cognitivos. Não há um perfil único de pessoa talentosa, pois é preciso considerar diferenças socioculturais, econômicas, raciais e de gênero na caracterização de um perfil talentoso. As mulheres talentosas, ou com alto potencial a ser desenvolvido, ainda estão subrepresentadas em diversas áreas e posições de destaque social" (PRADO; FLEITH; SOUZA, 2020, p. 3-4).
}

Quando na falta de apoio ou investimento e credibilidade nos seus potenciais e negócio, as mulheres têm buscado apoiar a si mesmas, reunindo as suas habilidades e trabalhando em prol de potencializar os seus projetos de modo a promover uma rede de acolhimento às demais, para que tenham as suas oportunidades determinadas por fatores alheios a sua vontade. Esse é um processo que as condicionam a depositar muita fé nelas mesmas porque não é fácil ser disruptivo em um meio social onde predomina 
tantos estigmas. Segundo Reis e Sullivan (2009), o processo para promover talentos femininos perpassa pelas escolhas responsáveis que considerem as suas especificidades femininas e que a sociedade tem responsabilidade na desconstrução dos estereótipos que impactam as mulheres e, com base nisso, fornecer a oportunidade para que essas mulheres possam se fortalecer e conseguir ultrapassar as barreiras que a desconstrução cultural impõe.

A representatividade gera o empoderamento. Esses fatores dão ensejo à busca por autonomia, liberdade e desenvolvimento. Isso alimenta a construção ideológica das mulheres sobre a valorização das suas habilidades e os seus talentos, o que tem sido possibilitado por iniciativa de rede de apoio promovidas por outras mulheres. Atualmente, no Brasil, conforme exposto neste trabalho, vem a ocorrer um progresso nos empreendimentos e esses têm ocupado espaços no mercado, gerando renda, promovendo sustentabilidade e mitigando vulnerabilidades. Rompendo os tais paradigmas e indo ao encontro do contrassenso, os negócios criativos além de serem altamente escaláveis são, sobretudo, importantes por fornecerem resultados que impactam à sociedade positivamente, preenchendo uma lacuna enorme deixada pela indústria, comércio, e pela inércia de iniciativas estatais que não implementam políticas de investimento efetivas, por considerar uma sedimentação de risco.

As mulheres, se querem algo, historicamente, têm que lutar por inúmeras vezes mais que os homens. Dada essa recorrência, têm desenvolvido habilidades necessárias para assumir as posições de liderança. Desse patamar de visibilidade, têm conseguido se destacar de modo a mudar a sua realidade e a de outras mulheres, construindo informalmente, porém legitima rede paralela de governança. Segundo GONÇALVES, Alcindo “a governança não é ação isolada da sociedade civil buscando maiores espaços de participação e influência. Ao contrário, o conceito compreende a ação conjunta de Estado e sociedade na busca de soluções e resultados para problemas comuns. Não obstante, é inegável que o surgimento dos atores não estatais é central para o desenvolvimento da ideia e da prática da governança"23.

Decorre de situações como essa a evidência da importância da liderança e

23 GONÇALVES, Alcindo. CONCEITO DE GOVERNANÇA. p.r4. Disponível em: http://www.egov.ufsc.brportal/sits/default/files/conceito_de_governança.pdf. Acesso em: II/o7/202I. 
representatividade feminina, pois a mulher tem uma característica peculiar de multiplicadora, seja na esfera corporativa, onde tem conseguido alcançar grandes resultados, seja na seara do empreendimento e na criação de negócios com impactos sociais. Essa é uma qualidade importante para promover a multiplicação de força de trabalho, de poder econômico e social e de desenvolvimento, pois as mulheres além de serem consumidoras, porque detêm grande poder de escolha de produtos, elas também são potenciadoras de geração de renda. Isso tem chamado atenção de instituições do setor privado, que apoiaram essas causas, depois de muita luta para conseguir provar a legitimidade da participação, a capacidade e o poder do empreendimento feminino. Esse tipo de interferência na sociedade tem grande relevância, pois representa a nova forma de governança da organização social, que, através desses novos atores, constituem a democracia participativa. Vale ressaltar que não cabe aqui confusos, pois, "governança não é o mesmo que governo”, assim preleciona (ROSENAU, 200o, p. 15), que explica "in verbis":

[... ] governo sugere atividades sustentadas por uma autoridade formal, pelo poder de polícia que garante a implementação das políticas devidamente instituídas, enquanto governança refere-se a atividades apoiadas em objetivos comuns, que podem ou não derivar de responsabilidades legais e formalmente prescritas e não dependem, necessariamente, do poder de polícia para que sejam aceitas e vençam resistências.

Para o autor, o conceito de governança não se restringe a uma simples nomenclatura. Seria a governança um fenómeno com maior abrangência que o conceito de governo, e que essa engloba outros mecanismos de caráter nãogovernamentais, que possibilitam a atuação de organizações e de pessoas dentro de uma mesma esfera possam ressarcir suas necessidades. ROSENAU (2000, p 15-16).

Então a atuação desses atores, bem como a sociedade civil e organizações nãogovernamentais acabam por preencher uma lacuna deixada pelo estado através de um certo modelo de governança institucional. Por isso a importância da participação da sociedade, trata-se, portanto, de um vetor de congregação de objetivos, mobilização e desenvolvimento social. "A sociedade civil organizada surge não como substituta das ações do Estado, mas como nova instância, que pode contribuir, apresentar propostas e influenciar positivamente as políticas governamentais na busca de mudanças sociais significativas" (SUCUPIRA, CHAVES e MONTEIRO, 2007, P.I). 
É preciso concretizar a ideia de "democratizar a democracia” (SANTOS, 2002), reconhecer o valor e o poder da democracia participativa e a importância de se pensar a possibilidade de fundi-la com a representativa de modo a potencializa-las através de um modelo que funcione nas demandas sociais do estado, ao invés de destituir uma em detrimento da outra, pois "a ampliação e aperfeiçoamento dos mecanismos de participação da democracia representativa se constituem em um desafio na consolidação da democracia participativa” (SUCUPIRA, CHAVES e MONTEIRO, 2007, p.14). Pois, a melhor maneira de enfrentar questões globais é através de "redes de temas globais”, ou seja, realçar a participação dos atores não-estatais de forma permanente e contínua, mas não necessariamente institucionalizada e formal, a partir de temas concretos, e da articulação informal de forças e redes que se constroem em cada caso" (GONÇALVES, Alcindo, p. 13).

O pensamento de BENEVIDES (I99I) coaduna com as ideias de GONÇALVES, quando expressa que a democracia representativa deixa a desejar quanto a concretização dos interesses da coletividade, bem como na transparência e prestação de contas, ocasionando o repúdio da sociedade que em resposta e para ressurgência se mobiliza e reivindicam a sua participação de modo que se integrem os mecanismos de representação estatal com o popular e efetive-se um modelo de governança cujo núcleo seja gerido por preceitos e finalidades verdadeiramente democráticos.

\section{CONCLUSÃO}

Atualmente, através dos empreendimentos, as mulheres aumentam a sua rede de apoio, criado inclusive as suas próprias fontes de financiamento, a exemplo das empresas anjos, que também vêm a trabalhar em cima da filosofia da busca da representatividade sem abandonar a essência do cooperativismo e solidariedade. Com isso, têm alcançado grandes resultados, embora os obstáculos cresçam a cada passo que conseguem dar, mas a resistência também é elemento característico delas e, por isso, persistem.

A realidade brasileira é de uma sociedade plural e com uma carência enorme 
em vários setores e coisas diversas, o que torna imprescindível qualquer ação que vise colaboração, redução de desigualdades causadas pelas lacunas deixadas por um modelo de governança ineficaz e uma filosofia de democracia paradoxalmente excludente que não conseguem resolver os seus problemas da sociedade.

Não se pode ignorar o papel do estado nessa relação entre ele e a sociedade civil e as suas organizações, muito menos deixar de reconhecer a importância da luta das minorias em prol dos seus direitos fundamentais e sociais. Se deve corresponder a expectativa de ser um ente integrador, facilitador e não um oponente, pois na representação do seu papel também empreendedor de forma, mais participativa, investir no capital, considerado de risco, onde as instituições privadas se esquivam, porque esse é seu papel. A sua magnitude contrai o ônus dos riscos em prol dos cumprimentos da sua responsabilidade.

Dito posto, resta o reconhecimento de que há a necessidade de uma rede integrada de parceria, para com a definição de políticas públicas possam se estruturar de modo a possibilitar a concretização de ações que efetivem direitos, e em grau de equidade, os das mulheres. Essa que, em meio a todos os fatores de interseccionalidade, buscam formas corajosas de ressurgência e o faz com princípios e valores sociais e solidários para com toda a sociedade. Também, da importância de se promover a integração de outros atores da sociedade civil e das esferas pública e privada para implementação de mecanismo de replicação de projetos de sucesso em outras regiões do Brasil, e assim disseminar a abertura para a participação popular na construção de espaços de mudança e decisão concernente as premissas de uma democracia eficaz.

\section{REFERÊNCIAS}

BEIJING, Quarta Conferência Mundial da Mulher, 1995. In: http://www. un.org/womennwatch/daw/Beijing/platform/index.html. Acessado em Io/o7/2021.

BENEVIDES, Maria V. de M. A cidadania ativa: eferendo, plebiscito e iniciativa popular. São Paulo: Ática, 199I.

FALCONER, A. P. A promessa do Terceiro Setor. Um Estudo sobre a construção do Papel das Organizações Sem Fins Lucrativos e do seu Campo de Gestão. Centro de Estudos de Administração do Terceiro Setor (CEATS), Faculdade de Economia, Administração e Contabilidade, Universidade de São Paulo, São Paulo, 2004. 
Favaro, C. (2007). Mulher e Família: Um Binômio (quase) Inseparável. In: Strey, M.N.; Neto, J.A.S. \& Horta, R.L. (org), Família e Gênero, Porto Alegre: EDIPUCRS.

FRIDEMANN, John. Empowerment Uma Política de Desenvolvimento Alternativo.Oeiras: Celta Editora, 1996.

GALEOTTI, Anna Elisabetta. Cidadania e diferença de gênero. O problema da dupla lealdade. In:. O problema da dupla lealdade. In:1995.

GONÇALVES, Alcindo. CONCEITO DE GOVERNANÇA. p.i4. Disponível em: http://www.egov.ufsc.brportal/sits/default/files/conceito_de_governança.pdf.

Acesso em: II/o7/202I.

Grant, W.H. (20or). A maternidade, o trabalho e a mulher. In: Colóquio do Lepsi IP/FEUSP, 3, São Paulo. Proceedings on line... Disponível em: http://www.proceedings.scielo.br/scielo.phpscript=sci_arttext\&pid=MSCoooooooo3 200100030 0008\&lng=en\&nrm=abn Acessado em: 09 de jul de 2021.

(Hunter, 2006, p. 18.). Hunter, J. C. (2006). Como se tornar um líder servidor: os princípios de liderança de o monge e o executivo. Rio de Janeiro: Sextante.

Leite, C.L.P. (1994). Mulheres: muito além do teto de vidro. São Paulo: Atlas.

OFFE, Clauss. Trabalho e sociedade: problemas estruturais e perspectivas para o futuro da "sociedade do trabalho". Rio de Janeiro: Tempo Brasileiro, 1989.

MAZZUCATO, Mariana, O Estado Empreendedor. São Paulo: Penguin, 2014.

Medeiros, Cíntia Rodrigues de Oliveira. Mulheres no terceiro setor : "mirem-se ... no exemplo... daquelas mulheres... de Atenas / Dissertação de mestrado. Universidade Federal de Uberlãndia, 2008.

Oliveira, A. L. O processo de empoderamento de mulheres trabalhadoras em empreendimentos de economia solidária. Dissertação de Mestrado em Serviço Social. Universidade Federal de Santa Catarina. Florianópolis, 2004. SCHUMPETER, J. Capitalism, Socialism and Democracy . Nova York: Routledge, 2003 [1942].

Prado, Renata Muniz e Fleith, Denise de Souza MULHERES TALENTOSAS NO BRASIL: TRAJETÓRIAS E DESAFIOS PROFISSIONAIS NA SOCIEDADE CONTEMPORÂNEAII Apoio e financiamento: Conselho Nacional de Desenvolvimento Científico e Tecnológico (CNPq). Psicologia em Estudo [online]. 2020, v. 25 [Acessado 3 Julho 2021], e469o6. Disponível em: 〈https://doi.org/I0.4025/psicolestud.v25io.46906〉. Epub i8 Maio 2020. ISSN I8070329. https://doi.org/10.4025/psicolestud.v25io.46906.

Reis, S. M., \& Sullivan, E. E. (2009). A theory of talent development in women of accomplishment. In L. V. Shavinina (Ed.), International handbook of giftedness (p. 
487-504). New York, NY: Springer.

SANTOS, B.S. Democratizar a democracia: os caminhos da democracia participativa. Rio de janeiro: Civilização Brasileira, 2002.

Silva, M. A. (200o). Todo poder às mulheres: esperança de equilíbrio para o mundo. São Paulo: Best Seller.

Subotnik, R. F., Olszewski-Kubilius, P., \& Worrell, F. C. (20II). Rethinking giftedness and gifted education: a proposed direction forward based on psychological science. Psychological Science, $12(\mathrm{I}), \quad 3-54 . \quad$ Recuperado de: http://dx.doi.org/Io.1177/1529100611418056,

Teykal, C. M., \& Coutinho, M. L. R. (2007). O homem atual e a inserção da mulher no mercado de trabalho. Psico, v. 38, n. 3, pp. 262-268. Recuperado de https://dialnet.unirioja.es/servlet/articulo?codigo $=5161629$

SUCUPIRA, Luciana Abranches. CHAVES, Alexandra Drabik. MONTEIRO, Maria Gabriela. ONGs e Estado: Entre a Retórica e a Prática Autoria. 2007. Disponível em :http://www.anpad.org.br/diversos/down_zips/33/APSA838.pdf 2007). Acesso em: $12 / 07 / 2021$. 